\title{
HUBUNGAN KEPERCAYAAN DENGAN PERILAKU MENCARI PERTOLONGAN PADA KELUARGA ORANG DENGAN GANGGUAN JIWA DI KOTA TERNATE
}

\author{
Sriyani Masita \\ Andi Buanasari \\ Wico silolonga \\ Program Studi Ilmu Keperawatan Fakultas Kedokteran \\ Univeristas Sam Ratulangi \\ Email : sriyanimasita2109@gmail.com
}

\begin{abstract}
Abstrack : Believe is the willingness of a party to trust the other party based on the expectation that the other party will take certain important actions to heal the family member. Help seeking behavior of individuals or groups who make a way to seek help, treatment in the community an be done by means of bringing individuals to helath services, help from sharmans or other alternatives The purpose of this study was to determine the relationship of trust with behavior seeking help in families of people with mental disorders in Ternate City. the method of This research uses descriptive analytic research design. Sampling technique uses purposive sampling technique with a total sample of 124 respondents. Results Spearman correlation test obtained significant value trust with help seeking behavior 0,000. The conclusions of the results of this study indicate that there is a relationship between stigma and trust with behavior seeking help in people with mental disorders a families.
\end{abstract}

Keywords: Mental disorders, trust, help seeking behavior

\begin{abstract}
Abstrak : Kepercayaan adalah kesediaan suatu pihak untuk mempercayai pihak lain didasarkan pada harapan bahwa pihak lain tersebut akan melakukan tindakan tertentu yang penting untuk menyembuhkan anggota keluarganya. Perilaku mencari pertolongan adalah suatu perilaku individu atau kelompok yang melakukan suatu cara untuk mencari pertolongan. Pengobatan di masyarakat bisa dilakukan dengan cara membawa individu ke pelayanan kesehatan, pertolongan dukun atau alternatif lainya. Tujuan penelitian untuk mengidentifikasi hubungan antara kepercayaan dengan perilaku mencari pertolongan pada keluarga orang dengan gangguan jiwa di kota Ternate. Metode penelitian ini menggunakan desain penelitian deskriptif analitik. Teknik pengambilan Sampel menggunakan teknik purposive sampling dengan jumlah sampel sebanyak 124 responden. Hasil dengan menggunakan uji spearman korelasi didapatkan nilai signifikan kepercayaan dengan perilaku mencari pertolongan 0,000. Kesimpulan hasil penelitian ini menunjukan bahwa terdapat hubungan antara kepercayaan dengan perilaku mencari pertolongan pada keluarga orang dengan gangguan jiwa.
\end{abstract}

Kata kunci : Gangguan jiwa, kepercayaan, perilaku mencari pertolongan 


\section{PENDAHULUAN}

Gangguan jiwa merupakan suatu penyakit yang dapat terjadi gangguan pola perilaku yang berkaitan dengan stress pada suatu fungsi kehidupan manusia (Keliat, 2011). Kejadian gangguan jiwa sekarang didunia sudah menjadi permasalahan yang sangat serius dan sangat mengkhwatirkan karena 1 dari 4 orang didunia pernah mengalami gangguan mental dan sekarang berkisar 450 juta orang diseluruh dunia pernah menderita gangguan jiwa, dan 8 dari 10 penderita gangguan mental itu tidak mendapatkan perawatan (World Health Organization, 2012). Keluarga orang dengan gangguan jiwa percaya bahwa gangguan jiwa berat yang berkaitan dengan kejadian supranatural munculnya pandangan di masyarakat beredar bahwa gangguan jiwa yang terjadi pada keluarganya disebabkan oleh roh jahat atau guna-guna dan mereka mencari bantuan ke non medis untuk mengatasi gejala gangguan jiwa yang dialami oleh anggota keluarganya (Ching \& Chen, 2016).

Anggota keluarga yang terkena gangguan jiwa akan berdampak pada pencarian pengobatan. Sering kali anggota keluarga tidak langsung membawa orang dengan gangguan jiwa ke professional kesehatan jiwa karena menganggap gangguan tersebut disebabkan oleh kerauhan (roh lain). Hasil penelitian dari Herdiyanto, dkk (2011) dampak stigma yang dirasakan oleh anggota keluarga orang dengan gangguan jiwa berdampak terhadap pengobatan orang dengan gangguan jiwa itu sendiri, semakin besarnya stigma yang dirasakan, maka proses untuk sembuh pada orang dengan gangguan jiwa akan semakin terganggu, yang dapat berbentuk perlakuan pembiaran orang dengan gangguan jiwa tanpa pengobatan medis, bahkan sampai menyebabkan tindakan pemasungan yang dilakukan oleh anggota keluarga orang dengan gangguan jiwa sendiri. Kesadaran dan persepsi masyarakat terhadap kesehatan mental berbeda disetiap kebudayaan suatu budaya tertentu, orang- orang secara sukarela mencari bantuan dari para professional untuk menangani gangguan jiwanya, sebaliknya dalam kebudayaan yang lain, gangguan jiwa cenderung diabaikan sehingga penanganan akan menjdi buruk karena tak ada perawatan khusus, atau di sisi lain masyarakat kurang antusias dalam mendapatkan bantuan untuk mengatasi gangguan jiwanya bahkan gangguan jiwa dianggap memalukan atau membawa aib bagi keluarga, persepsi yang timbul dimasyarakat disebabkan oleh gejala yang di angap aneh dan berbeda dari orang normal. Adanya persepsi ini juga berkaitan dengan faktor tradisi atau kebudayaan dalam masyarakat yang masih percaya takhayul dan tindakan irasional warisan nenek moyang. Selain itu, persepsi tersebut muncul karena penyebab gangguan jiwa itu sendiri dirasa sulit ditemukan (Simatauw, 2015). Keluarga orang dengan gangguan jiwa percaya bahwa gangguan jiwa berat yang berkaitan dengan kejadian supranatural (Ching \& Chen, 2016) munculnya pandangan di masyarakat beredar bahwa gangguan jiwa yang terjadi pada keluarganya disebabkan oleh roh jahat atau guna-guna dan mereka mencari bantuan ke non medis untuk mengatasi gejala gangguan jiwa yang dialami oleh anggota keluarganya (Pamungkas, 2016). Kendala yang terjadi pada pengobatan orang dengan gangguan jiwa yaitu kurangnya pengetahuan masyarakat dan keluarga, keluarga dan masyarakat sering kali menganggap bahwa orang dengan gangguan jiwa ialah suatu penyakit yang akan membawa aib bagi keluarga, maka keadaan ini diperberat dengan sikap keluarga yang cenderung mengisolasi dan mengucilkan bahkan bisa sampai dengan memasung (Sulastri, 2018).

Keluarga beranggapan bahwa penyakit yang dialami orang dengan gangguan jiwa yaitu penyakit menetap dan tidak bisa disembuhkan sehingga keluarga cenderung membiarkan pasien asal tidak menganggu (Marfuah \& Noviyanti, 2017). Menurut hasil penelitian dari Setiadi 
(2013), dalam memberikan pertolongan bagian keluarga yang paling penting yaitu ibu dan kakak, dan beberapa orang dengan gangguan jiwa lain yang tidak tinggal bersama dengan orang tuanya, dengan peran mencari pertolongan dilakukan oleh istri/suami sebagai pasangan hidup. Upaya pencarian pertolongan yang dilakukan keluarga dapat ditunjukan oleh berbagai sumber, antara lain kepada tetangga, tempat pengobatan tradisional, tempat pengobatan kepercayaan, pengobatan medis dan psikologis, hasil penelitian menunjukan bahwa keluarga tidak hanya mencari pertolongan atau bantuan pada satu tempat saja, keluarga lebih banyak memilih untuk mendapatkan bantuan pertama ke dokter spesialis kejiwaan/psikiatri dan menggunakan pengobatan tradisional dan kepercayaan secara bersamaan. Sementara sebagian keluarga menunjukan perilaku yang berbeda yaitu memilih untuk menanyakan masalahnya kepada pemuka agama terlebih dahulu kemudian mencari pengobatan medis yang lebih professional.

Perilaku mencari pertolongan adalah suatu perilaku individu atau kelompok yang melakukan suatu cara untuk mencari pertolongan (Notoadmojo, 2012). Pengobatan di masyarakat bisa dilakukan dengan cara membawa individu ke pelayanan kesehatan, pertolongan dukun atau alternatif lainya (Sarafino, 2011). Berdasarkan data yang didapatkan dari Dinas Kesehatan Kota Ternate terdapat bahwa pasien dengan orang dengan gangguan jiwa berat pada tahun 2016 berjumlah 62 orang, pada tahun 2017 berjumlah 50 orang dan pada tahun 2018 berjumlah 50 orang. Hasil wawancara yang dilakukan pada 5 keluarga orang dengan gangguan jiwa di Kota Ternate, dari hasil wawancara yang didapatkan rata-rata keluarga orang dengan gangguan jiwa mengatakan mereka percaya bahwa gangguan jiwa yang dialami anggota keluarganya akibat dari guna-guna (santet), mereka lebih percaya orang pintar (dukun) dapat menyembuhkan gangguan jiwa dari pada pergi ke pelayanan kesehatan terdekat seperti puskesmas karena faktor budaya di Kota Ternate yang masih sangat kental sehingga masyarakat Kota Ternate lebih percaya pada orang pintar (dukun) dari pada mencari pelayanan ke RS atau Puskesmas terdekat.

\section{METODE PENELITIAN}

Penelitian ini termasuk dalam jenis penelitian kuantitatif dengan menggunakan metode penelitian survei analitik untuk menganalisis hubunga kepercayaan dengan perilaku mencari pertolongan, Penelitian ini menggunakan desain penelitian cross sectional (Setiadi, 2013). Penelitian ini dilaksanakan di 8 puskesmas di Kota Ternate pada tanggal 18 Februari 2019. Populasi penelitian ini adalah keluarga yang mempunyai anggota keluarga gangguan jiwa sebanyak 180 keluarga. Pengambilan sampel menggunakan teknik purposive sampling dengan rumus slovin maka didapatkan jumlah sampel 124 responden. Instrument penelitian yang digunakan untuk mengukur variabel kepercayaan menggunakan kuesioner yang pernah digunakan sebelumnya oleh Lewis, 2010 di universitas negeri Florida Amerika Serikat dan telah diuji validitasinya dengan nilai reabilitas 0,871 dan di anggap baik dan layak digunakan, kuesioner kepercayaan terdiri dari 15 pertanyaan dengan pemberian bobot: apabila menjawab "Ya" di beri nilai 1, "Tidak" 0 , dan instrument penelitian yang digunakan untuk mengukur variabel perilaku mencari pertolongan menggunakan kuesioner

Yang diambil dari thesis sebelumnya oleh paulding, 2016 di amerika serikat dan telah diuji validitas dengan nilai reabilitas 0,871 dan dianggap baik dan layak untuk digunakan Kuesioner ini berjumlah 10 pertanyaan dengan pemberian bobot: apabila menjawab skor 1 sangat tidak setuju (sts), skor 2 tidak setuju (ts), skor 3 setuju (s) dan skor 4 sangat setuju (ss). Setelah lembar kuesioner di isi oleh responden, peneliti mengumpulkan kembali lembar kuesioner 
Pengolahan data yang diperoleh dari hasil penelitian ini dianalisis menggunakan uji statistik melalui sistem komputerisasi dengan beberapa tahap yaitu editing, coding, tabulasi data (Notoatmodjo, 2010). Analisa bivariat dalam penelitian ini yaitu untuk mengetahui hubungan kepercayaan dengan perilaku mencari pertolongan pada keluarga orang dengan gangguan jiwa di Kota Ternate. Peneliti menggunakan uji Korelasi spearman dengan tingkat kemaknaan 100\% $(\alpha=$ 0,000).

\section{HASIL dan PEMBAHASAN}

\section{Karakteristik Responden}

Tabel 1. Distribusi Responden berdasarkan umur

\begin{tabular}{ccc}
\hline Umur & $\mathrm{n}$ & $\%$ \\
\hline 20-40 Tahun & 5 & 4,0 \\
41-60 Tahun & 91 & 73,4 \\
61-80 Tahun & 28 & 2,6 \\
\hline Total & 124 & 100
\end{tabular}

Sumber : Data Primer, 2019

Hasil penelitian menunjukan dari jumlah responden sebanyak 124 orang, didapati sebagian besar responden berumur 41-60 tahun berjumlah 91 responden $(73,4 \%)$ hasil ini sesuai dengan penelitian yang dilakukan oleh Pamungkas (2016) dimana umur responden mungkin mempengaruhi bagaimana individu memandang gangguan jiwa dengan konsep yang berbeda. Menurut Notoadmojo (2003) bahwa usia yang dianggap optimal dalam mengambil keputusan adalah usia diatas 20 tahun. Dimana semakin bertambah usia seseorang maka semakin mampu menunjukan kematangan jiwa, semakin bijaksana dalam mengambil keputusan, mampu berpikir rasional, mampu mengendalikan emosi dan makin toleran terhadap orang lain.
Tabel 2. Karakteristik responden bersadarkan jenis kelamin.

\begin{tabular}{ccc}
\hline Jenis Kelamin & $\mathrm{n}$ & $\%$ \\
\hline Laki-laki & 47 & 37,9 \\
Perempuan & 77 & 62,1 \\
\hline Total & 124 & 100 \\
\hline
\end{tabular}

Sumber : Data Primer, 2019

Berdasarkan tabel 2 karakteristik jenis kelamin responden perempuan lebih banyak dengan jumlah 77 orang $(62,1 \%)$ dibandingkan laki-laki yang berjumlah 47 orang $(37,9 \%)$.

Tabel 3. karakteristik Karakterisrik responden berdasarkan pekerjaan di Kota Ternate pada bulan Februari 2019

\begin{tabular}{ccc}
\hline Pekerjaan & $\mathrm{n}$ & $\%$ \\
\hline Buruh & 21 & 16,9 \\
IRT & 56 & 44,4 \\
Pedagang & 1 & 8 \\
Petani & 11 & 8,9 \\
PNS & 29 & 23,4 \\
Swasta & 2 & 1,6 \\
Wirastawasta & 5 & 4,0 \\
\hline Total & 124 & 100
\end{tabular}

Sumber: Data Primer, 2019

Berdasarkan tabel 3 Karakteristik pekerjaan paling banyak adalah ibu rumah tangga (IRT) dengan jumlah 56 responden $(44,4 \%)$.

Tabel 4. Karakterisrik responden berdasarkan pendapatan di Kota Ternate pada Bulan Februari 2019

\begin{tabular}{ccc}
\hline Pendapatan & $\mathrm{n}$ & $\%$ \\
\hline$<2.000 .000$ & 92 & 74,2 \\
$>2.000 .000$ & 32 & 25,8 \\
\hline Total & 124 & 100 \\
\hline
\end{tabular}

Sumber: Data primer, 2019

Berdasarkan tabel 4 pada karakteristik pendapatan yang diperoleh, sebagian besar reponden memiliki pendapatan dibawah dua juta berjumlah 92 orang $(74,2 \%)$ 
2. Distribusi frekuensi

Tabel 5. Kepercayaan keluarga orang dengan gangguan jiwa

\begin{tabular}{ccc}
\hline Kepercayaan & $\mathrm{n}$ & $\%$ \\
\hline Negatif & 124 & 100 \\
\hline Positif & 0 & 0 \\
\hline Total & 124 & 100 \\
\hline
\end{tabular}

Sumber : Data Primer, 2019

\begin{abstract}
Berdasarkan tabel 5 diketahui bahwa sebanyak 124 responden mengalami kepercayaan yang negatif, yang dimaksud dengan kepercayaan yang negatif yaitu kepercayaan masyarakat di Kota Ternate masih sangat kuat untuk mempercayai orang pintar (dukun) untuk menyembuhkan anggota keluarganya yang mengalami gangguan jiwa.
\end{abstract}

Tabel 6. Perilaku mencari pertolongan pada keluarga orang dengan gangguan jiwa

\begin{tabular}{ccc}
$\begin{array}{c}\text { Perilaku } \\
\text { mencari } \\
\text { pertolongan }\end{array}$ & $\mathrm{n}$ & $(\%)$ \\
\hline $\begin{array}{c}\text { Rendah } \\
\text { Tinggi }\end{array}$ & 74 & 59,7 \\
\hline Total & & 40,3 \\
\hline
\end{tabular}

Sumber : Data Primer, 2019

Berdasarkan tabel 6 diketahui bahwa perilaku mencari pertolongan keluarga orang dengan gangguan jiwa pada pelayanan kesehatan (Puskesmas) memiliki perilaku mencari pertolongan yang rendah sebanyak 74 responden $(59,7 \%)$. Responden lebih banyak mencari pertolongan di orang pintar (dukun) untuk menyembuhkan anggota keluarganya yang mengalami gangguan jiwa.

\section{Analisa Bivariat}

Tabel 7. Hubungan kepercayaan dengan perilaku mencari pertolongan pada keluarga orang dengan gangguan jiwa

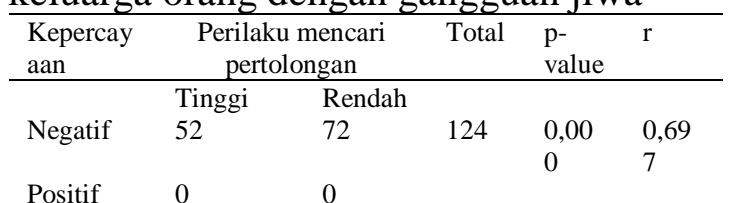

Sumber : Data Primer, 2019

Berdasarkan tabel 7 diketahui nilai signifikan sebesar $0,000(p<0,05)$ hal ini menunjukan adanya hubungan yang signifikan antara kepercayaan dengan perilaku mencari pertolongan dengan koefisien korelasi spearman (r) sebesar 0,697 yang menunjukan koefisien korelasi kuat dan bernilai positif. Maka kedua variabel mempunyai hubungan yang searah. Penelitan yang dilakukan oleh Lubis (2016) di masyarakat beredar kepercayaan atau mitos yang salah mengenai gangguan jiwa, ada yang percaya bahwa gangguan jiwa disebabkan oleh roh jahat, ada yang menuduh bahwa itu akibat guna-guna, karena kutukan atau hukuman atas dosanya. Kepercayaan yang salah ini hanya akan merugikan penderitaan dan keluarganya karena pengidap gangguan jiwa tidak mendapatkan pengobatan secara cepat dan tepat.

Menurut Yusuf (2017) dalam penelitiannya tentang "fenomenologi pasung dan dukungan keluarga terhadap orang dengan gangguan jiwa" keluarga merupakan sumber bantuan praktis bagi pasien dalam pemenuhan kebutuhannya. Bentuk batuan jasa yang diberikan keluarga dengan mengambilkan obat ke rumah sakit. Bantuan ini di berikan karena ketidak mampuan pasien untuk dapat pergi sendiri ke pelayanan kesehatan. biaya waktu dan tenaga untuk mengambil obat di rumah sakit menjadi tanggung jawab keluarga. Penelitian sebelumnya dilakukan oleh Fairuzahida (2017) dalam penelitiannya tentang "perilaku keluarga dalam pengasuhan orang dengan gangguan jiwa" mengatakan masih banyak keluarga 
yang kurang dalam mencari pengobatan kepada orang dengan gangguan jiwa, sehingga masalah gangguan jiwa yang bisa diatasi sejak dini menjadi sulit dalam penanganannya karena kurangnya kepedulian dari keluarga untuk memperoleh pengobatan terhadap orang dengan gangguan jiwa. Penilaian masyarakat terhadap gangguan jiwa sebagai akibat guna-guna, santet, kutukan dan sejenisnya. Dampak dari kepercayaan masyarakat dan keluarga, upaya pengobatan klien gangguan jiwa dibawah berobat kedukun atau paranormal. Kondisi ini memperberat dengan sikap keluarga yang cenderung mempermalukan klien dengan disembunyikan, diisolasi, dukucilkan bahkan sampai ada yang dipasung (Hawari, 2014)

\section{SIMPULAN}

Hasil penelitian menunjukan adanya hubungan antara kepercayaan dengan perilaku mencari pertolongan, hal ini menyatakan bahwa kepercayan yang dianut oleh masyarakat Kota Ternate masi sangat kuat, sebab hal itulah semakin rendah keluarga untuk mencari pertolongan (medis)

\section{DAFTAR PUSTAKA}

Ching Wu.H, Chen. F. (2016). Sociocultural Factors Associated with Caregiver-Psychiatrist Relationship in Taiwan Psychiatry Investig. Psikiatri Investig 13 (3): 288-296

Fairuzahida, N.N. (2017). Perilaku Keluarga dalam Pengasuhan Orang dengan Gangguan Jiwa di Kecamatan Kanigoro Kabupaten Blitar. Jurnal Keperawatan. Volume 4. No.3

Hawari. (2014). Skizofrenia Pendekatan Holistik (BPSS) Bio-Psiko-SosialSpiritual Edisi Ketiga. Jakarta: Badan Penerbit Fakultas Kedokteran Universitas Indonesia.

Herdyianto, Tobing \& Vembrianti. (2017). Stigma Terhadap Orang Dengan
Gangguan Jiwa di Bali. Jurnal Psikologi.Volume 8. No. 2. http://journal.paramadina.ac.id/index. php/inquiry/article/view/148.

Keliat, B. Helena, N \& Frida, P. 2011. Manajemen Keperawatan Psikososial dan Kader Kesehatan Jiwa: CMHN (Basic Course). Jakarta: EGC

Lubis,. N. (2016). Pemahaman Masyarakat tentang Gangguan Jiwa dan Keterlambatan Mental. . Jurnal Jiwa Volume $4 . \quad$ No. 2. fisip.unpad.ac.id/jurnal/index.php/sha re/article/download/39/25.http://dx.do i.org/10.24198/swj.v4i2.39

Marfuah, D., Noviyanti, RD. 2017. Kemampuan Keluarga Merawat Pasien Skizofrenia Dengan Gejala Halusinasi. The $\sigma^{\text {th }}$ university Research Colloquium 2017, Universitas Muhammadiyah Magelang.

Notoadmodjo, S. (2010). Metodologi Penelitian Kesehatan, Jakarta:Rineka Cipta

Notoadmojo, S. (2003). Promosi Kesehatan dan Ilmu Perilaku. Jakarta: Rineka Cipta

Notoadmodjo (2012). Pendidikan dan Perilaku Kesehatan. Jakarta: Rineka Cipta

Pamungkas, D. (2016). kepercayaan Terhadap Orang dengan Gangguan Jiwa Pada Mahasiswa Program Studi Ilmu Keperawatan Stikes Jendral Ahmad Yani. Jurnal Kesehatan. Volume 5. No 2

Sulastri. (2018). Kemampuan Keluarga dalam Merawat Orang dengan Gangguan Jiwa. Jurnal Kesehatan. Volume 9. No. 1

Sarafino. (2011). Health Psychology :Biopsychosocial Interactions. Fifth Edition.USA : John Wiley \& Sons 
e-journal Keperawatan(e-Kp) Volume 7 Nomor 1, Mei 2019

Simatauw, vanesa sepriany, 2015.

Pengaruh stigma dan kebudayaan terhadap pasien gangguan jiwa di RSKD Ambon,

Setiadi, (2013), Konsep dan Praktek Penulisan Riset Keperawatam, Edisi 2, Yogyakarta; Graha Ilmu

WHO (2012). Health education: Theoretical concepts, effective strategies and corecompetencies. Cairo: WHO Regional Office for the Eastern Mediterranean Publishers.

Yusuf,.A. (2017) Fenomen a Pasung dan Dukungan Keluarga terhadap Pasien Gangguan Jiwa Pasca Pasung. Jurnal Keperawatan. Volume 5 Nomor 3 